\title{
NOTÍCIAS DO I.U.D.P.S
}

Das actividades desenvolvidas no âmbito do IUDPS, durante o ano lectivo 2000/2001, destacam-se:

- As I Jornadas de Gestão e Informática de Gestão subordinadas ao tema "As novas economias", promovidas pelos alunos das duas licenciaturas ministradas no IUDPS (Gestão e Desenvolvimento Social e Informática de Gestão), em colaboração com a Associação Académica de Viseu da Universidade Católica Portuguesa de Viseu. Estas jornadas decorreram nos dias 23 e 24 de Novembro de 2000, no auditório Eng. Engrácia Carrilho, do Pólo de Viseu do Centro Regional da Beiras;

- A conclusão da celebração dos "20 anos de presença em Viseu da Universidade Católica Portuguesa", com encerramento solene a 30 de Novembro de 2000

- A abertura do Curso de Mestrado em Administração Escolar e Administração Educacional, em Novembro de 2000, tendo-se concluído, durante este ano lectivo 2000/2001, a leccionação da parte curricular.

- "Dia Aberto" da iniciativa do Gabinete da Coordenação de Estágios, que se realizou a 31 de Maio de 2001, em que se promoveu o contacto dos Alunos e Universidade e Organizações do meio empresarial nomeadamente: A. Figueiredo Lopes, Albuquerque e Freitas S.A., AIRV - Associação Industrial da Região de Viseu, AIA - Associação Industrial de Águeda, Caja Duero, Câmara Municipal de Viseu, Europeia de Seguros Winthertur, Ficosa Internacional HufPortuguesa, Imoleasing, IEFP - Instituto de Emprego e Formação Profissional, Grupo Visabeira.

- A sessão solene de Bênção e Entrega de Diplomas aos licenciados do Pólo de Viseu do Centro Regional das Beiras da Universidade Católica que teve lugar a 13 de Julho de 2001 na Igreja do Seminário Maior de Viseu e contou com a presença do Reitor, prof. Doutor Manuel Braga da Cruz.

Maria Cristina Sousa Gomes 